\title{
Analysis of the results of invasive diagnostic procedures in patients referred to gynecologic department due to abnormal uterine bleeding
}

\author{
Malwina Soja, Martyna Masternak, Iwona Piwowarczyk, Łukasz Janas, Krzysztof Szyłło, Marek Nowak \\ Department of Operative Gynecology and Gynecologic Oncology, Polish Mother's Memorial Hospital Research Institute, Lodz, Poland
}

\begin{abstract}
Introduction: Abnormal uterine bleeding (AUB) is one of the most common reason for visits to gynecologists. Endometrial biopsy is a routine procedure in gynecological practice to detect the etiology of AUB and to exclude precancerous and cancerous lesions of the endometrium. The aim of this study was to assess the causes of AUB among women, who had undergone invasive diagnostics due to AUB.

Material and methods: This study was carried among 531 women, who had undergone invasive diagnostics due to AUB between January 2018 and December 2018. Women were divided into premenopausal (with perimenopausal) and postmenopausal groups. Transvaginal ultrasound was performed. Endometrial thickness was compared with histopathological results in each subgroup and statistically analyzed. The incidence of histopathological findings and rate of anemia were also analyzed.

Results: In our series of patients the most common cause of AUB based on histopathological results was endometrial polyp, both before and after menopause. The most frequent pathologies at ultrasound findings were leiomyomas and endometrial polyps. The incidence of taken together: atypical hyperplasia and endometrial cancer was significantly higher in postmenopausal group (8.58\%) than in pre- and perimenopausal (1.35\%, $p=0.0001$ ). The median endometrial thickness, both before and after menopause, was significantly greater in patients with pathological than with nonpathological endometrium. 31\% of women with abnormal uterine bleeding before menopause and $10 \%$ after menopause had anemia.

Conclusions: Measurements of endometrial thickness seems to be acceptable initial diagnostic tool to distinguish between benign and pathological endometrial changes both before and after menopause.
\end{abstract}

Key words: AUB, premenopause, perimenopause, postmenopause, TVS, anemia, endometrial polyps, hyperplasia, endometrial cancer.

\section{Introduction}

Abnormal uterine bleeding (AUB) is one of the most common gynecologic health issues, which has a significant impact on quality of life and its physical, emotional and social spheres [1]. It can lead to anemia, syncope, injuries and be the reason for work absence [2]. Finally, it may be the manifestation of precancerous and cancerous lesions of the endometrium. AUB is defined as any variation from the normal menstrual cycle, which includes prolonged or excessive bleeding, irregular bleeding, intervals of less than 21 days and greater than every 35 days and intermenstrual bleeding [3]. The etiology of abnormal uterine bleeding can vary widely, hence the International Federation of Gynecology and Obstetrics working group on menstrual disorders developed a classification system in non-gravid womenPALM-COEIN. In general we can distinguish two main groups: structural, which can be assessed with imaging techniques (PALM - polyp, adenomyosis, leiomyoma, malignancy and hyperplasia) and nonstructural (COEIN - coagulopathy, ovulatory dysfunction, endometrial, iatrogenic and not yet classified) [4]. AUB affects women of all ages, but occurs most frequently in the peri- and postmenopausal period. Perimenopause is the time of women's life of natural shift from regular bleeding to anovulatory cycles with irregular and frequently excessive menstruation and eventually permanent infertility [5]. It usually starts 2-8 years before menopause and ends one year after [6]. Endometrial biopsy preceded by taking medical history, clinical examination and transvaginal ultrasound is a routine procedure in gynecological practice. Invasive diagnostics, according to ACOG (The American College of Obstetricians and Gynecologists) should be performed in women with AUB older than 45 years and before that age with a history of unopposed estrogen exposure, failed medical treatment 
and persistent AUB [7]. The aim of this study was to assess the causes of abnormal uterine bleeding among women who had undergone invasive diagnostics due to abnormal uterine bleeding.

\section{Material and methods}

This is a retrospective study of women who underwent invasive diagnostics (dilatation and curettage of the cervical canal and uterine cavity, hysteroscopy, resection of polyps, endometrial biopsies) because of abnormal uterine bleeding between January 2018 and December 2018 in gynecologic department. Women were divided into two subgroups: premenopausal (with perimenopausal) and postmenopausal. Patients without ultrasound examination performed in the department prior to the procedure and procedures performed due to obstetric indications were excluded. Transvaginal ultrasound results included the assessment of myometrium (suspicion of adenomyosis, presence of leiomyomas), endometrium (endometrial thickness and suspicion of endometrial polyps) and ovaries (presence of functional cysts, endometriomas and other tumors). Histopathological findings were classified into two main groups: nonpathological and pathological. Nonpathological group consists of physiological endometrium (secretory or proliferative phase and atrophic endometrium), endometrial polyps, abnormal physiological changes (pill endometrium, irregular shedding, disordered proliferative endometrium and pseudodecidualization), other (suspicion of adenomyosis and inflammation of endometrium) and unsatisfactory for evaluation. Pathological group consists of hyperplasia with or without atypia, endometrial polyps with hyperplasia without atypia,

Table 1. Basic characteristic of the studied groups of patients

\begin{tabular}{lcc}
\hline Ultrasound results & $\begin{array}{c}\text { Premenopausal } \\
(n=297)\end{array}$ & $\begin{array}{c}\text { Postmenopausal } \\
(n=233)\end{array}$ \\
\hline $\begin{array}{l}\text { Heterogeneous } \\
\text { myometrium } \\
\text { with small } \pm \text { multiple } \\
\text { leiomyomas }\end{array}$ & $55(18.52)$ & $62(26.61)$ \\
\hline Leiomyoma & $96(32.32)$ & $54(23.18)$ \\
\hline \multicolumn{1}{c}{ Submucosal } & $13(4.38)$ & $7(3.00)$ \\
\hline$\quad$ Intramural & $58(19.53)$ & $37(15.88)$ \\
\hline \multicolumn{1}{c}{ Subserosal } & $25(8.42)$ & $10(4.29)$ \\
\hline $\begin{array}{l}\text { Endometrial polyp } \\
\text { susp. }\end{array}$ & $124(41.75)$ & $89(38.20)$ \\
\hline Ovarian lesions & $32(10.77)$ & $18(7.73)$ \\
\hline \multicolumn{1}{c}{ Functional cyst } & $20(6.73)$ & $3(1.29)$ \\
\hline \multicolumn{1}{|c}{ Endometrioma } & $8(2.69)$ & 0 \\
\hline \multicolumn{1}{c}{ Other tumors } & $4(1.35)$ & $15(6.44)$ \\
\hline Adenomyosis susp. & $2(0.67)$ & $4(1.72)$ \\
\hline Data are given as $n(\%)$ & &
\end{tabular}

hyperplasia with atypia or carcinoma in polyps and endometrial carcinoma. The incidence of histopathological findings was analyzed by the $\chi^{2}$ test. Endometrial thickness was compared with histopathological results in each subgroup and statistically analyzed using median test. The rate of anemia was also analyzed.

\section{Results}

531 women who had undergone invasive diagnostic procedures because of abnormal uterine bleeding were included in the study. 298 (56\%) were premenopausal and perimenopausal and 233 (44\%) were postmenopausal.

Based on transvaginal ultrasound, results leiomyomas were described in $50.84 \%$ of women before menopause and $49.79 \%$ of women after menopause. Heterogeneous myometrium with small multiple leiomyomas was detected in $18.52 \%$ and larger leiomyomas in $32.32 \%$ of premenopausal women with AUB. In postmenopausal women these groups constituted of $26.61 \%$ and $23.18 \%$ patients with AUB, respectively. Endometrial polyps were described in $41.75 \%$ of women before menopause and $38.20 \%$ after menopause, ovarian lesions $-10.77 \%$ vs. $7.73 \%$ and adenomyosis $-0.67 \%$ vs. $1.72 \%$. Table 1 shows ultrasound results.

The analysis of pathomorphological results revealed, that the most common histological result in the nonpathological group was endometrial polyp - 36.24\% of women before menopause and $42.49 \%$ of women after menopause.

Apart from endometrial polyp, in nonpathological group, the most frequent histological findings were physiological endometrium (33.56\% in pre- and $36.48 \%$ in postmenopausal women) and abnormal physiological changes $(11.74 \%$ and $3 \%$, respectively). In pathological group, the most common findings were hyperplasia with and without atypia and endometrial cancer (12.41\% and $1 \%$ in pre- and $5.58 \%$ and $7.3 \%$ in postmenopausal women respectively). Histopathological results are presented in details in Figure 1. The incidence of taken together: atypical hyperplasia and endometrial cancer was significantly higher in postmenopausal group (8.58\%) than in pre- and perimenopausal $(1.34 \%$, $p=0.0001)$.

The median endometrial thickness before menopause was significantly greater in patients with pathological than with nonpathological endometrium (13 mm vs. $8 \mathrm{~mm}, p=0.0001$ ). Likewise, the median endometrial thickness in patients after menopause was significantly greater in patients with pathological than with nonpathological endometrium (11 mm vs. $7 \mathrm{~mm}$, $p=0.0007$ ) (Table 2).

The mean hemoglobin level in patients before menopause was $12.7 \mathrm{~g} / \mathrm{dl}$ and $13.7 \mathrm{~g} / \mathrm{dl}$ after menopause. $31 \%$ of women before menopause and 10\% after menopause had hemoglobin level below $12 \mathrm{~g} / \mathrm{dl}$ 


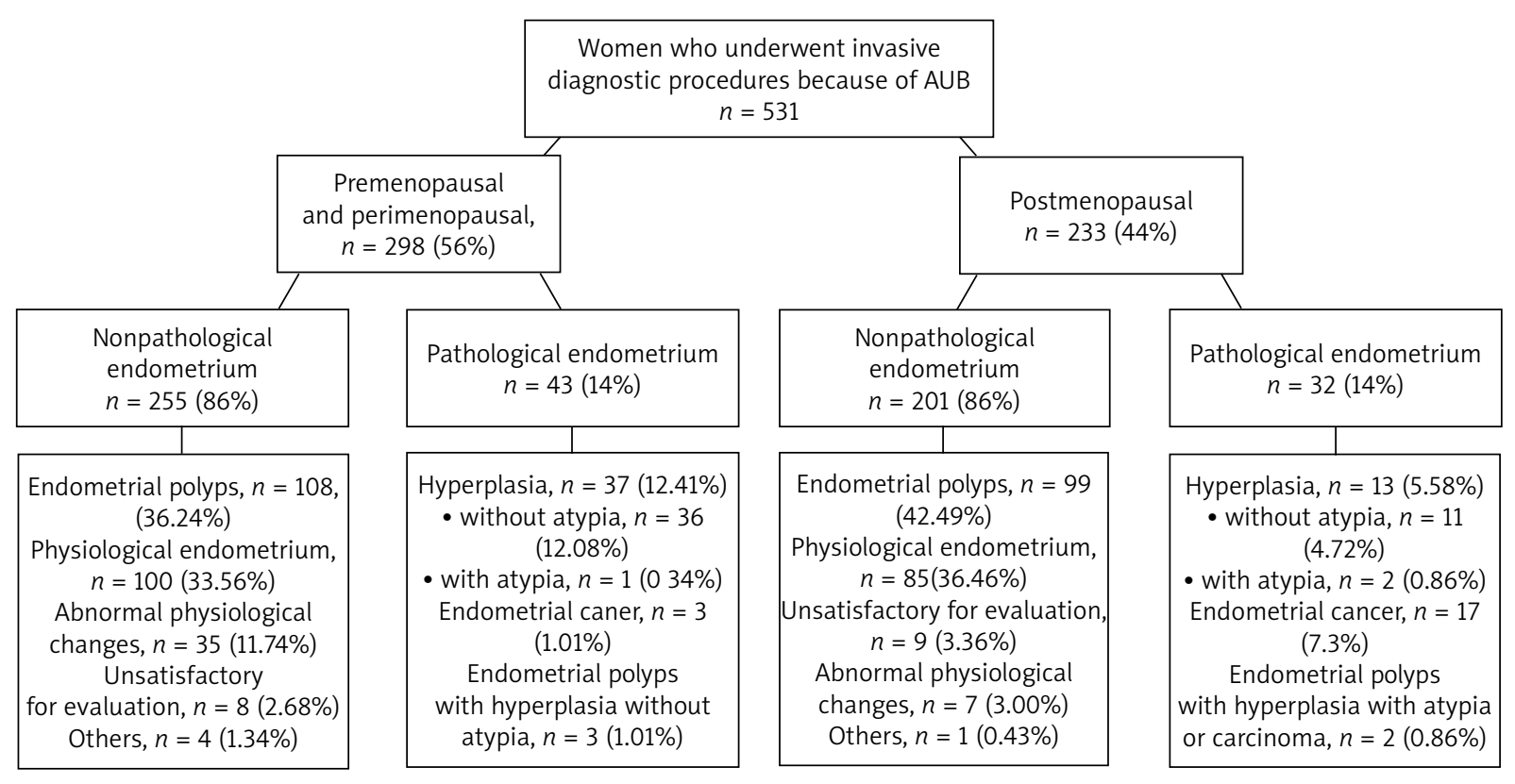

Fig. 1. Histopathological results

( $p=0.0001$ ). $1.34 \%$ patients before menopause and $0.43 \%$ after menopause had level of hemoglobin below $7 \mathrm{~g} / \mathrm{dl}$ (Table 3).

\section{Discussion}

The majority of women with abnormal uterine bleeding in our study had nonpathological histological results of endometrium. The most common cause of abnormal uterine bleeding, both before and after menopause, was endometrial polyp. Hyperplasia with atypia and malignancy were significantly more common in the postmenopausal women. These results correspond with the previous studies conducted in other countries [8-10].

Table 2. Comparison of endometrial thickness with histopathological results

\begin{tabular}{lc}
\hline Histopathological results & $\begin{array}{c}\text { Median endometrial } \\
\text { thickness }(\mathrm{mm}) \\
\text { [interquartile range] }\end{array}$ \\
\hline Premenopausal & $8[6-11]$ \\
\hline Nonpathological & $13[9-16]$ \\
\hline Pathological & $13[9-16]$ \\
\hline Hyperplasia & $9[7-13]$ \\
\hline Endometrial cancer & $7[4-10]$ \\
\hline Postmenopausal & $11[7.5-21]$ \\
\hline Nonpathological & $7.75[5.4-13]$ \\
\hline Pathological & $17[8.6-28]$ \\
\hline Hyperplasia &
\end{tabular}

Endometrial polyps may develop both in women of reproductive age and after menopause [11]. They are among the most common causes of abnormal uterine bleeding [10]. In this study endometrial polyps occurred in $39 \%$ of cases. That proportion is slightly higher than reported by Van den Bosch et al., who detected endometrial polyps in about $26 \%$ of patients with AUB [12]. In the majority of cases polyps are benign, nevertheless 0.5 to $13 \%$ may turn out hyperplastic or show malignant transformation [13, 14]. Carcinomatous transformation occurs more frequently among postmenopausal women with hypertension and obesity $[15,16]$. Our study reported three endometrial polyps with hyperplasia without atypia in premenopausal group and one polyp with hyperplasia with atypia and one carcinoma in polyp (patient had hypertension) in postmenopausal group.

Uterine leiomyomas are benign tumors of the uterus, which affect about $60-70 \%$ of women of all ages [17, 18]. Most of them are asymptomatic, but about $25-40 \%$ of myomas can cause heavy menstrual bleeding, pelvic pain or infertility $[19,20]$. We can distinguish three main type of leiomyomas - submucosal, intramural and subserosal, still more clinically practical classification splits leiomyomas into submucosal and others, because it is generally considered, that the first ones are the

Table 3. Hemoglobin level among premenopausal and postmenopausal group

\begin{tabular}{lcc}
\hline Hemoglobin level & Premenopausal & Postmenopausal \\
\hline Mean $(\mathrm{g} / \mathrm{dl})$ [range] & $12.7[4-15.7]$ & $13.7[5-15.8]$ \\
\hline Below $12 \mathrm{~g} / \mathrm{dl}$ & $\mathrm{n}=91(31 \%)$ & $\mathrm{n}=23(10 \%)$ \\
\hline Below $7 \mathrm{~g} / \mathrm{dl}$ & $\mathrm{n}=4(1.34 \%)$ & $\mathrm{n}=1(0.43 \%)$ \\
\hline
\end{tabular}


most likely to contribute to abnormal uterine bleeding [4]. In this study $50 \%$ of women had myomas according to ultrasound findings.

Endometrial hyperplasia is a common gynecologic diagnosis, histologically defined as the presence of proliferation of the endometrial glands resulting in an increase in gland-to-stroma ratio [21]. It is also recognized as precursor lesion of endometrial cancer (endometrioid type). Doherty et al., in their metanalysis, reported the risk of non-atypical hyperplasia progression to cancer at annual incidence rate at $2.6 \%$ and atypical hyperplasia at $8.2 \%$ [21]. Abnormal uterine bleeding is the most common symptom of endometrial hyperplasia and cancer [22, 23]. Transvaginal ultrasound, because of accessibility and low cost, is the first-line imaging technique in diagnosis of the pathology of endometrium. Endometrial thickness among postmenopausal women with abnormal uterine bleeding below 3-5 mm seems to have very high negative predictive value for endometrial cancer [24, 25]. Unfortunately, there is no established consensus and standardized cut off for endometrial thickness for premenopausal women [22, 26, 27]. In this study, endometrium was significantly thicker in women with endometrial hyperplasia or cancer that in patients with nonpathological histopathological findings (in both pre- and postmenopausal group).

Anemia, which is defined in women as hemoglobin level less than $12 \mathrm{~g} / \mathrm{dl}$, is often caused by abnormal uterine bleeding. The presence or absence of anemia helps to determine the severity of the condition and the proper treatment. Matteson et al. revealed in their study, that thirty-five percent of women, seeking urgent medical attention for abnormal uterine bleeding, were anemic [28]. In the present study, hemoglobin level below $12 \mathrm{~g} / \mathrm{dl}$ occurred in 31\% of women before menopause and 10\% after menopause, but only $1.34 \%$ women before menopause and $0.43 \%$ after menopause had laboratory indications for blood transfusions (level of hemoglobin below $7 \mathrm{~g} / \mathrm{dl}$ ).

\section{Conclusions}

In our series of patients the most common cause of abnormal uterine bleeding based on histopathological results was endometrial polyp, both before and after menopause. Hyperplasia with atypia and malignancy were significantly more common in the postmenopausal women. The most frequent pathologies at ultrasound findings were leiomyomas and endometrial polyps. Measurements of endometrial thickness seems to be acceptable initial diagnostic tool to distinguish between benign and pathological endometrial changes both before and after menopause. Abnormal uterine bleeding is a frequent reason for anemia.

\section{Disclosure}

The authors report no conflict of interest.

\section{References}

1. NICE. Assessment and management of heavy menstrual bleeding. NICE Clin Guidel [NG88]. 14 March 2018. Last updated 31 March 2020.

2. Kai J, Middleton L, Daniels J, et al. Usual medical treatments or levonorgestrel-IUS for women with heavy menstrual bleeding: long-term randomised pragmatic trial in primary care. Br J Gen Pract 2016; 66: e861e870

3. Oriel KA, Schrager S. Abnormal uterine bleeding. Am Fam Physician 1999; 60: 1371-1380.

4. Munro MG, Critchley HOD, Broder MS, Fraser IS. FIGO classification system (PALM-COEIN) for causes of abnormal uterine bleeding in nongravid women of reproductive age. Int J Gynecol Obstet 2011; 113: 3-13.

5. Goldstein SR, Lumsden MA. Abnormal uterine bleeding in perimenopause. Climacteric 2017; 20: 414-420.

6. Nicula R, Diculescu D, Lencu CC, et al. Accuracy of transvaginal ultrasonography compared to endometrial biopsy for the etiological diagnosis of abnormal perimenopausal bleeding. Med Pharm Reports 2017; 90: 33-39.

7. Bulletins Gynecology. C on P. Practice Bulletin No. 128:diagnosis of abnormal uterine bleeding in reproductive-aged women. Obstet Gynecol. 2012;120(1):197-206.

8. Vaidya S, Lakhey M, Vaidya S, et al. Histopathological pattern of abnormal uterine bleeding in endometrial biopsies. Nepal Med Coll J 2013; 15: 74-77.

9. Soleymani E, Ziari K, Rahmani O, et al. Histopathological findings of endometrial specimens in abnormal uterine bleeding. Arch Gynecol Obstet 2014; 289: 845-849.

10. Sun $Y$, Wang $Y$, Mao L, et al. Prevalence of abnormal uterine bleeding according to new International Federation of Gynecology and Obstetrics classification in Chinese women of reproductive age. Medicine (Baltimore) 2018; 97: e11457.

11. Rešlová T, Tošner J, Rešl M, Kugler R, Vávrová I. Endometrial polyps. A clinical study of 245 cases. Arch Gynecol Obstet 1999; 262: 133-139.

12. Van den Bosch T, Ameye L, Van Schoubroeck D, et al. Intra-cavitary uterine pathology in women with abnormal uterine bleeding : a prospective study of 1220 women. Facts Views Vis Obgyn 2015; 7: 17-24.

13. Hileeto D, Fadare O, Martel M, Zheng W. Age dependent association of endometrial polyps with increased risk of cancer involvement. World J Surg Oncol 2005; 3: 6-11.

14. For the Italian School of Minimally Invasive GynecologicaL Surgery (SiCMiG) Hysteroscopists Group. Prevalence and predictors of atypical histology in endometrial polyps removed by hysteroscopy: A secondary analysis from the SICMIG hysteroscopy trial. Facts, views Vis ObGyn 2019; 11: 127-134.

15. Giordano G, Gnetti L, Merisio C, Melpignano M. Postmenopausal status, hypertension and obesity as risk factors for malignant transformation in endometrial polyps. Maturitas 2007; 56: 190-197.

16. Nijkang NP, Anderson L, Markham R, Manconi F. Endometrial polyps: Pathogenesis, sequelae and treatment. SAGE Open Med 2019; 7 : 205031211984824.

17. Stewart E, Cookson C, Gandolfo R, Schulze-Rath R. Epidemiology of uterine fibroids: a systematic review. BJOG An Int J Obstet Gynaecol 2017; 124: 1501-1512.

18. Okolo S. Incidence, aetiology and epidemiology of uterine fibroids. Best Pract Res Clin Obstet Gynaecol 2008; 22: 571-588.

19. Monleón J, Cañete ML, Caballero V, et al. Epidemiology of uterine myomas and clinical practice in Spain: An observational study. Eur J Obstet Gynecol Reprod Biol 2018; 226: 59-65.

20. Pérez-López FR, Ornat L, Ceausu I, et al. EMAS position statement: Management of uterine fibroids. Maturitas 2014; 79: 106-116.

21. Doherty MT, Sanni OB, Coleman HG, et al. Concurrent and future risk of endometrial cancer in women with endometrial hyperplasia: A systematic review and meta-analysis. Beiki O, ed. PLoS One 2020; 15: e0232231. 
22. Saccardi C, Vitagliano A, Marchetti M, et al. Endometrial Cancer Risk Prediction According to Indication of Diagnostic Hysteroscopy in Post-Menopausal Women. Diagnostics 2020; 10: 257.

23. Espindola D, Kennedy KA, Fischer EG. Management of Abnormal Uterine Bleeding and the Pathology of Endometrial Hyperplasia. Obstet Gynecol Clin North Am 2007; 34: 717-737.

24. Timmermans A, Opmeer BC, Khan KS, et al. Endometrial Thickness Measurement for Detecting Endometrial Cancer in Women With Postmenopausal Bleeding. Obstet Gynecol 2010; 116: 160-167.

25. Gupta JK, Chien PFW, Voit D, et al. Ultrasonographic endometrial thickness for diagnosing endometrial pathology in women with postmenopausal bleeding: a meta-analysis. Acta Obstet Gynecol Scand 2002; 81 799-816.

26. Getpook C, Wattanakumtornkul S. Endometrial thickness screening in premenopausal women with abnormal uterine bleeding. J Obstet Gynaecol Res 2006; 32: 588-592.

27. Park YR, Lee SW, Kim Y, et al. Endometrial thickness cut-off value by transvaginal ultrasonography for screening of endometrial pathology in premenopausal and postmenopausal women. Obstet Gynecol Sci 2019; 62: 445 .

28. Matteson KA, Raker CA, Pinto SB, et al. Women presenting to an emer gency facility with abnormal uterine bleeding: patient characteristics and prevalence of anemia. J Reprod Med 2015; 57: 17-25. 